\title{
Chlorophyll enhancement in the central region of the Bay of Biscay as a result of internal tidal wave interaction
}

\author{
S. Muacho a,b,1 , J.C.B. da Silva ${ }^{\text {c,d }}$, V. Brotas ${ }^{\text {b,e }}$, P.B. Oliveira a , J.M. Magalhaes ${ }^{\text {c,d,* }}$ \\ a IPMA, Instituto Português do Mar e da Atmosfera, Rua C do Aeroporto, 1749-077 Lisbon, Portugal \\ b Centre of Oceanography, Faculty of Science, University of Lisbon, Campo Grande, 1749-016, Lisbon, Portugal \\ c CIMAR/CIIMAR - Interdisciplinary Centre of Marine and Environmental Research, Porto, Portugal \\ d Department of Geosciences, Environment and Spatial Planning, University of Porto, Porto, Portugal \\ e Plymouth Marine Laboratory, Prospect Place, PL1 3DH Plymouth, UK
}

\section{A R T I C L E I N F O}

\section{Article history:}

Received 17 March 2014

Received in revised form 25 March 2014

Accepted 30 March 2014

Available online 5 April 2014

\section{Keywords:}

Internal waves

SAR

MODIS

Chlorophyll concentrations

Bay of Biscay

\begin{abstract}
A B S T R A C T
A multi-sensor satellite approach based on ocean colour, sunglint and Synthetic Aperture Radar imagery is used to study the impact of interacting internal tidal (IT) waves on near-surface chlorophyll-a distribution, in the central Bay of Biscay. Satellite imagery was initially used to characterize the internal solitary wave (ISW) field in the study area, where the "local generation mechanism" was found to be associated with two distinct regions of enhanced barotropic tidal forcing. IT beams formed at the French shelf-break, and generated from critical bathymetry in the vicinities of one of these regions, were found to be consistent with "locally generated" ISWs. Representative case studies illustrate the existence of two different axes of IT propagation originating from the French shelf-break, which intersect close to $46^{\circ} \mathrm{N},-7^{\circ} \mathrm{E}$, where strong IT interaction has been previously identified. Evidence of constructive interference between large IT waves is then presented and shown to be consistent with enhanced levels of chlorophyll-a concentration detected by means of ocean colour satellite sensors. Finally, the results obtained from satellite climatological mean chlorophyll-a concentration from late summer (i.e. September, when ITs and ISWs can meet ideal propagation conditions) suggest that elevated IT activity plays a significant role in phytoplankton vertical distribution, and therefore influences the late summer ecology in the central Bay of Biscay.
\end{abstract}

(c) 2014 Elsevier B.V. All rights reserved.

\section{Introduction}

Tidal flow over irregular bottom topography forces vertical motions at the tidal frequencies, and generates Internal Waves (IWs) with a tidal period, which under stratified conditions will then propagate along the thermocline as interfacial waves and are often referred to as Internal Tides (ITs). While propagating away from their generation site, ITs can steepen and generate IWs of much shorter period that are usually termed Internal Solitary Waves (ISWs) or "trains of solitons". These shorter IWs, whose periods can reach several tens of minutes, are termed 'solitary' since they tend to occur in individual packets (usually trapped in the troughs of the ITs), and have often been identified with the soliton solutions of nonlinear wave theory.

Large ITs and ISWs have already been extensively studied in the Bay of Biscay (see Fig. 1 for location) and are amongst the most energetic anywhere in the world (see e.g. Baines, 1982). In this region, the

\footnotetext{
* Corresponding author at: Department of Geosciences, Environment and Spatial Planning, University of Porto, Porto, Portugal.

E-mail address: jmagalhaes@fc.ul.pt (J.M. Magalhaes).

1 Present afilliation: IPMA - Instituto Português do Mar e da Atmosfera|CCMAR, Rua C do Aeroporto, 1749-077 Lisbon, Portugal.
}

internal tidal energy generated at the shelf-break has been documented to radiate away horizontally in the form of interfacial ITs, and to form internal tidal beams that propagate into the deep stratified ocean below. Therefore, large interfacial ITs will form in the thermocline directly above the shelf-break, and evolve (through nonlinear processes) to higher-frequency ISWs packets that propagate both offshore and inshore (see e.g. New and da Silva, 2002). However, the IT energy propagating downward into the deep ocean may also originate a second generation mechanism known as "local generation" (Akylas et al., 2007; da Silva et al., 2009; Gerkema, 2001; Grisouard et al., 2011; Mercier et al., 2012; New and da Silva, 2002; New and Pingree, 1992). In this case, a beam (or ray) of IT energy is generated at the shelf-break where the bottom slopes match the characteristic slopes of the IT beams (i.e. critical slopes), and then propagates into the deep ocean. In the Bay of Biscay, it is well known that these rays reflect from the seafloor (Pingree and New, 1989, 1991) and interact with the thermocline from below, causing large IT oscillations there, and "locally" generating ISWs some $150 \mathrm{~km}$ offshore from the shelf-break where the beam is initially generated. This process is also known as "beam scattering" into the pycnocline.

Previous studies using remote sensing data (Pingree and New, 1995) and in situ measurements (Pingree et al., 1986) have documented the 

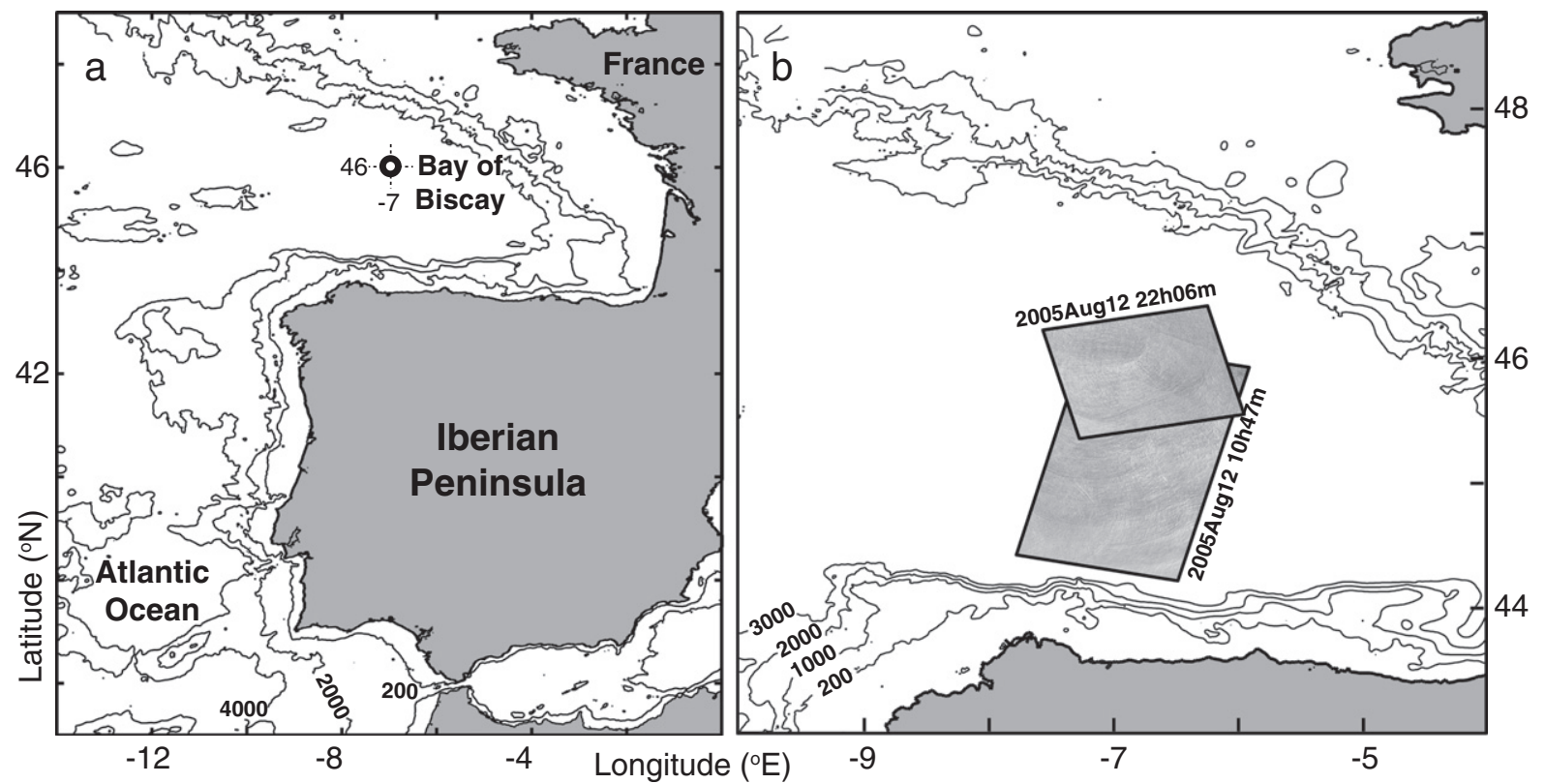

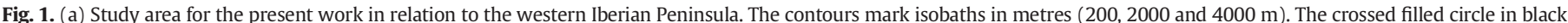

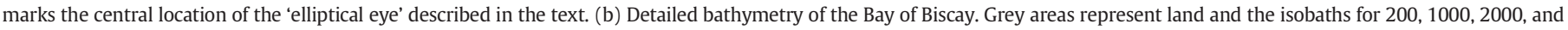
$3000 \mathrm{~m}$, are shown in black contours. For reference, two black rectangles are used to frame the Envisat-ASAR images discussed in the text.

presence of ITs in the central region of the Bay of Biscay, especially during late summer and after spring tide events. In the upper water column, the ITs appear as coherent features with wavelengths reaching from 30 to $50 \mathrm{~km}$, and produce vertical oscillations of the seasonal thermocline of up to $30 \mathrm{~m}$ in amplitude. During the summer, they have been observed by Pingree et al. (1986) to travel from the northern shelfbreak of the Bay of Biscay into the deep ocean with typical propagation speeds of around $1.0 \mathrm{~ms}^{-1}$.

Also important, is the geometry of the Bay of Biscay (when considering the region's isobaths), where the form of an elliptical "eye" was first noted by Pingree and New (1995), centred near $46{ }^{\circ} \mathrm{N}$ and $-7{ }^{\circ} \mathrm{E}$ (see Fig. 1). This was recognised as suggesting the presence of enhanced and localized IT waves. They conjectured that this "elliptical eye" could result from the intersection between ITs generated by an almost elliptical shelf-break arc, which is located either north or south at about 170-200 km from its centre. Based on in situ observations and modelling results, Pichon et al. (2013) reinforced this idea by revealing IT interactions consistent with the "eye's" location (around $46{ }^{\circ} \mathrm{N}$, $-7^{\circ} \mathrm{E}$ ), which involved IT beams coming from different generation spots sited over the northern (French) shelf-break.

The existence of large ITs and their possible interaction may be particularly relevant from a biological point of view, since their propagation induces a natural vertical motion within the water column, focused mainly near the pycnocline, which forces water particles to undergo upward and downward motions. This means that neutrally buoyant phytoplankton cells, which are usually passive in relation to these waves' time scales, can be significantly displaced vertically. It is also important to note that, under typically stratified conditions, levels of surface nutrients may become depleted, following the spring bloom, and thus leaving behind a chlorophyll subsurface maximum near the thermocline (see Harlay et al., 2010, 2011). Therefore, in the Bay of Biscay, as well as many other locations in the North Atlantic Ocean, a Deep Chlorophyll Maximum (DCM) often occurs in the summer. This in turn means that the presence of IT activity may displace the top of the DCM and lift it upwards where the effective light is just enough to produce a measurable response in ocean colour satellite sensors (see da Silva et al., 2002; Vázquez et al., 2009).

Significant coupling between ITs and phytoplankton dynamics has already been reported using in situ measurements (e.g., Gaxiola-
Castro et al., 2002; Sangra et al., 2001). The use of satellite SAR images and chlorophyll-a concentration products from the Sea-viewing Wide Field-of-view Sensor (SeaWiFS) in the central region of Bay of Biscay, also lead da Silva et al. (2002) to document the synergetic surface expressions of IT crests both in the SAR and in chlorophyll-a surface images. More recently, in-situ and Moderate-resolution Imaging Spectroradiometer (MODIS) data presented by Wang et al. (2007) and Pan et al. (2012) showed increased levels of chlorophyll-a in two different regions of the South China Sea, which were explained as a result of IT activity. Finally, Muacho et al. (2013) also reported the same phenomenon in the Nazaré Canyon (west of the Iberian Peninsula), where the role of large-amplitude ITs in increasing primary production was verified using both in situ and satellite data together with an analytic model.

This paper aims to present a typical case study, where SAR surface expressions of locally generated ISWs (i.e. by beam scattering into the thermocline) can be seen propagating in two separate directions, and thus be associated with distinct IT beams originating from the northern shelf break of the Bay of Biscay. These ISWs are used to infer the locations of their corresponding IT troughs and crests within the central Bay of Biscay, where ITs are already known to be amplified because of their nonlinear interactions (see Pichon and Correard, 2006; Pichon et al., 2013). Interestingly, the location of this interaction is also consistent with the location where Pingree and New (1995) observed their elliptical "eye" (approximately at $46^{\circ} \mathrm{N},-7^{\circ} \mathrm{E}$ and marked with a filled circle in Fig. 1a). Therefore, the main aim of the paper is to assess the impact of this region's elevated IT activity (and the interactions therein) on surface chlorophyll-a concentrations, measured by ocean colour remote sensors, both via daily (level 2) images and climatological data (from 2002 to 2011).

This paper is organized as follows. A SAR analysis begins by describing the 2D surface spatial structure of the IW field in the central region of the Bay of Biscay. A particular case study is used to highlight a region where ITs are likely to interact. The most probable generation mechanism is identified for two different families of ISWs, one of which has not yet been reported in the literature. We then investigate the influence of IT interactions on surface chlorophyll-a satellite data, and compare our findings with those coming from modelling results. The paper ends with some relevant discussions and conclusions. 


\section{SAR analysis}

The following analysis is based on a selection of two Envisat-ASAR images covering the central Bay of Biscay. The images were acquired in the summer period, when stratification conditions are known to be favourable for ISWs propagation, and a few days after the spring tides when ISWs are more frequently observed. SAR images are able to detect ISWs and hence reveal the location of their corresponding ITs crests and troughs. For a detailed explanation on the ability of the SAR to reveal the locations of ITs and ISWs refer to works done by Alpers (1985), Thompson and Gasparovic (1986), Ermakov et al. (1998), da Silva et al. (1998) and New and da Silva (2002).

A SAR image is presented in Fig. 2a, which is representative of the 2D horizontal structure of the ISWs in the central Bay of Biscay (see also Fig. 1b for location). The image was acquired from the Envisat-ASAR on August 12, 2005, at 22 h 06 m UTC, approximately four days after spring tides. At least four well developed ISW packets can be clearly identified as a series of dark bands on a generally grey background. These are labelled A and B according to their different travelling directions, which according to the SAR image are approximately from $155^{\circ} \mathrm{T}$ to $165^{\circ} \mathrm{T}$ for the A-type waves, and $205^{\circ} \mathrm{T}$ for the B-type waves (where ${ }^{\circ} \mathrm{T}$ means propagation directions measured from the true North).

Note that, propagation directions for ISWs can be easily inferred from SAR imagery since the rank-ordered amplitudes within a wave is a consequence of nonlinearity, which dictates that the largest amplitude waves propagate faster. Therefore, the largest radar signature within a given packet will correspond to the largest amplitude soliton. Thus, the ISWs propagation direction (i.e. that of the corresponding IT) is set to be perpendicular to the waves' crests, and such that largest signatures follow ahead of the smaller waves.

Further inspection of Fig. 2a reveals that the wave packets of group A are separated, along their apparent propagation path, by distances of roughly $45 \mathrm{~km}$. This can be translated into average propagation speeds of $1.0 \mathrm{~m} \cdot \mathrm{s}^{-1}$, if a semi-diurnal period is assumed between $A_{1}$ and $A_{2}$. The same order of separation distances can be found for $B$ waves, which correspond to propagation speeds of approximately $1.1 \mathrm{~m} \cdot \mathrm{s}^{-1}$ (see labels $B_{1}$ and $B_{2}$ ). Similar propagation speeds for the ITs have also been reported by Pingree et al. (1986), for typical summer stratification in the central Bay of Biscay. Note also that, these well-developed trains travelling close to $46^{\circ} \mathrm{N},-7^{\circ} \mathrm{E}$, already contain individual waves with along crest-lengths of up to $60 \mathrm{~km}$.

The SAR image in Fig. 2b is very similar to Fig. 2a and was acquired farther south by the Envisat-ASAR, still on the same day but at $10 \mathrm{~h} 47$ m UTC (for clarity, both images are overlaid in Fig. 1b). This means that the time difference between them corresponds to approximately a semi-diurnal tidal period, and thus the spatial structure of the ISWs on either image would remain fairly the same if a semi-diurnal tidal cycle were to be added or subtracted from either of the image acquisitions times. This is important when assuming that the waves shown in Fig. 2a could be interpreted as the predecessors of the waves shown in Fig. 2b, even despite these being in the reversed order. Just like in Fig. 2a, Fig. 2b also has at least four well developed ISW packets, which were also labelled $A$ and $B$ according to their different travelling directions. A closer inspection of Fig. 2b reveals similar propagations directions for both types of waves and similar propagation speeds for A-type waves, when comparing with those inferred from Fig. 2a.

It should be noted that, these two propagation axes (i.e. groups $\mathrm{A}$ and B) as well as their associated IT waves, converge together in the region previously described by Pingree and New (1995) as the "elliptical eye", which is also in good agreement with the recent modelling results presented by Pichon et al. (2013). The SAR images thus confirm that there is a region (near $46{ }^{\circ} \mathrm{N},-7{ }^{\circ} \mathrm{E}$ ) where the convergence of two ITs occurs, and where we expect the IT wave crests and troughs to interfere constructively (see Fig. 2a and b), thus resulting in enhanced vertical displacements.
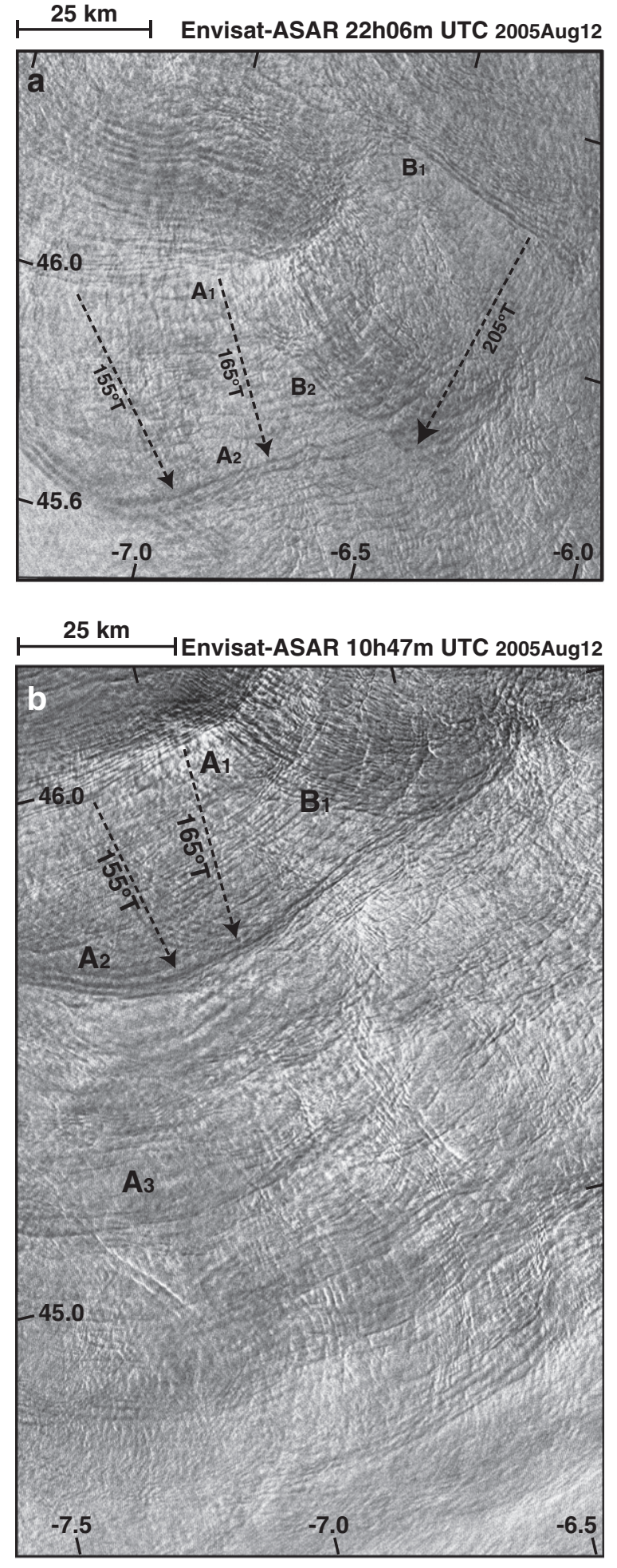

Fig. 2. (a) Subset of an Envisat-ASAR image dated 12 August 2005 (acquired at $22 \mathrm{~h} 06 \mathrm{~m}$ UTC), showing ranked-ordered ISW packets propagating in the central Bay of Biscay. The ISW packets are labelled A and B according to their propagation directions and marked chronologically (i.e. indices 1 and 2 render a generation timeline from the most recent to the eldest). (b) Same as part (a) but for the Envisat-ASAR image acquired earlier the same day at $10 \mathrm{~h} 47 \mathrm{~m}$ UTC. See Fig. 1 for locations.

However, before investigating possible effects of this IT superposition on surface chlorophyll-a concentrations, the authors first recall that the ISWs propagating towards the southwest (i.e. about $205^{\circ} \mathrm{T}$ ) agree well with the directions of propagation reported in New and da Silva (2002, see e.g. their Fig. 7). In fact, previous studies have already 
reported the local generation of ISWs in the central Bay of Biscay, and revealed several hotspot locations (i.e. generation sites) such as the northern continental shelf break (see e.g., New and da Silva, 2002) and the Ortegal Promontory in the southern Bay of Biscay (Azevedo et al., 2006; da Silva et al., 2007). Nevertheless, the origin of the other set of wave packets (labelled A in Fig. 2a), seems to remain undocumented in the literature until now.

To investigate the generation mechanism for A-type waves, we now turn to the analysis combining IT ray tracing techniques and the barotropic forcing term presented in Baines (1982). This procedure has been previously used (see e.g. Azevedo et al., 2006; da Silva et al., $2007,2009)$ to investigate the effectiveness of the local generation mechanism both in the Bay of Biscay, as well as in other regions of the world's oceans. While ray tracing diagrams provide the expected pathways of the IT beams, the Baines (1982) barotropic forcing term serves as a proxy to identify the most likely hotspots for IT generation. On the one hand, ray tracing diagrams are essentially assuming that the energy in ITs (in a continuously stratified fluid) can be described by characteristic pathways, which have and angle $(\theta)$ to the horizontal according to:

$\tan (\theta)= \pm\left(\frac{\sigma^{2}-f^{2}}{N^{2}-\sigma^{2}}\right)^{1 / 2}$

where $N$ is the Brunt-Väisälä frequency, $\sigma$ is the tidal frequency, and $f$ is the Coriolis parameter. On the other hand, the forcing term (or body force $F$ ) describes the interaction between the barotropic tides and the steep bottom topography, and can be written as:

$F=z N^{2}(z) \int_{t 1}^{t 2}(u h, v h) d t . \vec{\nabla}(1 / h)$

where $z$ is the upward vertical direction, $N$ is again the local BruntVäisälä frequency, $u$ and $v$ are the zonal and meridional components of the barotropic velocity, and $h$ is the ocean depth. The body force $F$ can thus be analytically integrated between any two times $t_{1}$ and $t_{2}$ provided that $u$ and $v$ are known (for a detailed description of the forcing term please see also da Silva et al., 2009, and the references therein).

In the present work, the components of the barotropic velocity vector were obtained for the same date as Fig. $2 \mathrm{a}$, from the $1 / 12^{\circ}$ resolution tidal model OTIS (Oregon State University Tidal Inversion Software, version 7.2), developed by Egbert and Erofeeva (2002), using all diurnal and semi-diurnal tidal constituents. The barotropic velocity vectors for a complete tidal cycle were then interpolated to the Smith and Sandwell (1997) 1 min bathymetry grid. Finally, the stratification $N$ (assumed spatially constant) was obtained by averaging all the available September stratifications in the Bay of Biscay (between $-9{ }^{\circ} \mathrm{E}$ and $-5{ }^{\circ} \mathrm{E}$ and between $44^{\circ} \mathrm{N}$ and $48^{\circ} \mathrm{N}$, available at http://www. nodc.noaa.gov/OC5/WOD05/pr_wod05.html).

A subset of the maximum depth-integrated body force over a complete tidal cycle is shown in Fig. 3a, together with the positions of the leading waves of each ISW packet observed in the SAR images in Fig. 2 (in blue for Fig. 2a and green for Fig. 2b). The authors anticipate that the positions of these waves are consistent with the local generation mechanism, resulting from the interaction of tidal beams with the seasonal thermocline (considered here to be at about $50 \mathrm{~m}$ depth). Note that, New and da Silva (2002) have shown that a large number of ISWs observed in the Bay of Biscay appear to be locally generated from IT beams emanating from the shelf break between $-5.4^{\circ} \mathrm{E}$ and $-6.4^{\circ} \mathrm{E}$ (i.e. near G2 in Fig. 3a), and then propagate offshore in the southwest direction. This description agrees well with our B-type waves, which are seen to travel bearing $205^{\circ} \mathrm{T}$. We therefore interpret these ISWs as resulting from IT beams formed close to the position labelled $\mathrm{G}_{2}$ (see Fig. 3a).

However, the propagation direction of the A-type waves suggests a generation region much farther to the west than that of group B, and likely associated with the stronger region of elevated forcing
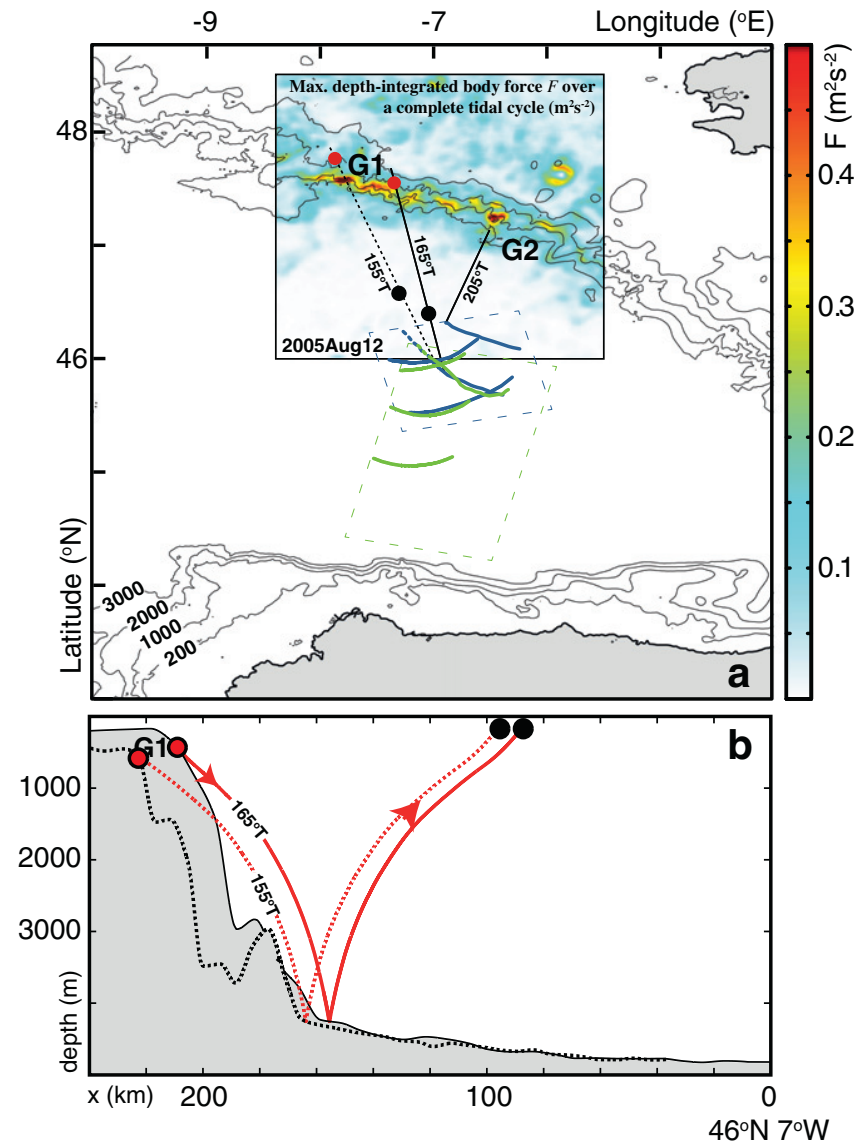

Fig. 3. (a) Detailed bathymetry of the Bay of Biscay (as in Fig. 1b), shown together with a subset of the maximum Baines (1982) depth-integrated body force over a complete tidal cycle (calculated using Eq. (2)) for 12 August 2005. The leading waves for each packet in Fig. 2a and b are also shown (in blue and green lines, respectively) with their associated propagation directions. Two distinct maxima are labelled $G_{1}$ and $G_{2}$. The expected surfacing of the IT beams leaving from the critical bathymetry near G1 (see red dots) are marked with filled black circles, which are seen close to, but still preceding the locations of the ISWs. (b) Vertical sections showing IT beams for two representative cases where the SAR observations are consistent with local generation. Two distinct rays can be seen emanating from critical topography (in red circles), and reaching the thermocline some $140 \mathrm{~km}$ further into the deep ocean (see black circle).

labelled $\mathrm{G}_{1}$. To investigate this location as a plausible generation hotspot for A-type waves, we computed the (semidiurnal) IT ray paths emanating from critical topography surrounding $G_{1}$ (see red dots in Fig. 3). According to Fig. 3b, these rays propagate down into the deep ocean, and reflect from the sea bottom to interact later with the thermocline some $140 \mathrm{~km}$ farther south-southeast (see black dots in Fig. 3). This analysis thus reinforces the hypothesis of local generation (i.e. ISWs generated by beam scattering into the thermocline), since appropriate rays taken along the A-waves' propagation directions appear close to, but still upstream of their "earliest observed" positions (i.e., more to the north-northwest, since propagation is south-southeast). It is interesting to note that our results indicate that the forcing near $G_{1}$ is much more widespread, when compared with $G_{2}$. At the same time, the steep shelf-break topography in the Bay of Biscay allows for critical bathymetry to be easily found near $\mathrm{G}_{1}$. In fact, the two IT paths plotted in Fig. 3b aim only to represent a much broader number of IT beams leaving $G_{1}$, the majority of which can be traced close to (but still behind, i.e. to the North of) the earliest observations of A-type waves. This is particularly relevant, since a closer inspection of the wave signatures taken from the SAR imagery also indicates several packets coming from this location, but having slightly different propagation directions (see Fig. 2). At the same time, the inter-packet separations typical for 
the semi-diurnal internal tide can only be clearly found in Fig. $2 b$ between $A_{1}$ and $A_{2}$. After that (see e.g. around $A_{3}$ ), the sea surface signatures of more than one set of waves (at least two) give the impression of inter-packet separations approximately half of a typical $\mathrm{M}_{2}$ period, which is again consistent with several ITs being generated from $\mathrm{G}_{1}$.

According to the analysis summarized in Fig. 3, both groups of ISWs shown in Fig. 2 are being locally generated in the central Bay of Biscay (near $46^{\circ} \mathrm{N},-7^{\circ} \mathrm{E}$ ) by beams of IT energy originating from the shelfbreak and consistent with elevated regions of barotropic tidal forcing. Therefore, the geometry of $G_{1}$ and $G_{2}$ is in agreement with the elliptical 'eye' suggested by Pingree and New (1995) and further supported by Pichon et al. (2013) and reveals the central Bay of Biscay as a converging "point" for the interference of ITs.

\section{Ocean colour observations}

To investigate a possible relation between IT activity and enhanced chlorophyll concentration levels, a careful analysis of near-surface chlorophyll-a concentration images (based on level-2 NASA Ocean Colour products) was performed, which were acquired by the MODIS ocean colour sensor, aboard the Aqua satellite, and covered the central region of the Bay of Biscay (i.e. from 45 to $47^{\circ} \mathrm{N}$, and between -8.5 and $-5.5^{\circ} \mathrm{E}$ ). Unfortunately, the satellite data coincident with the SAR observations presented in Fig. 2 are fully contaminated by clouds.

However, a very similar case to that presented in Fig. 2 can also be observed in a sunglint image acquired just 3 days after spring tides, on September 14, 2003 at $13 \mathrm{~h}$ UTC. The level-1B products from the MODIS-Aqua satellite have a nominal spatial resolution of $250 \mathrm{~m}$, and can therefore be used to detect the sea surface signatures of ISWs (for more details on the ability of MODIS images to reveal the location of ISWs see e.g. Jackson, 2007; Jackson and Alpers, 2010). The positions of the leading wave fronts for each ISW train observed in this particular case are plotted in Fig. 4 (see solid black lines), together with the corresponding near-surface levels of chlorophyll-a concentrations derived from the level-2 product (with a nominal $1.1 \mathrm{~km}$ spatial resolution). Note that, in this case the image is almost cloud-free.

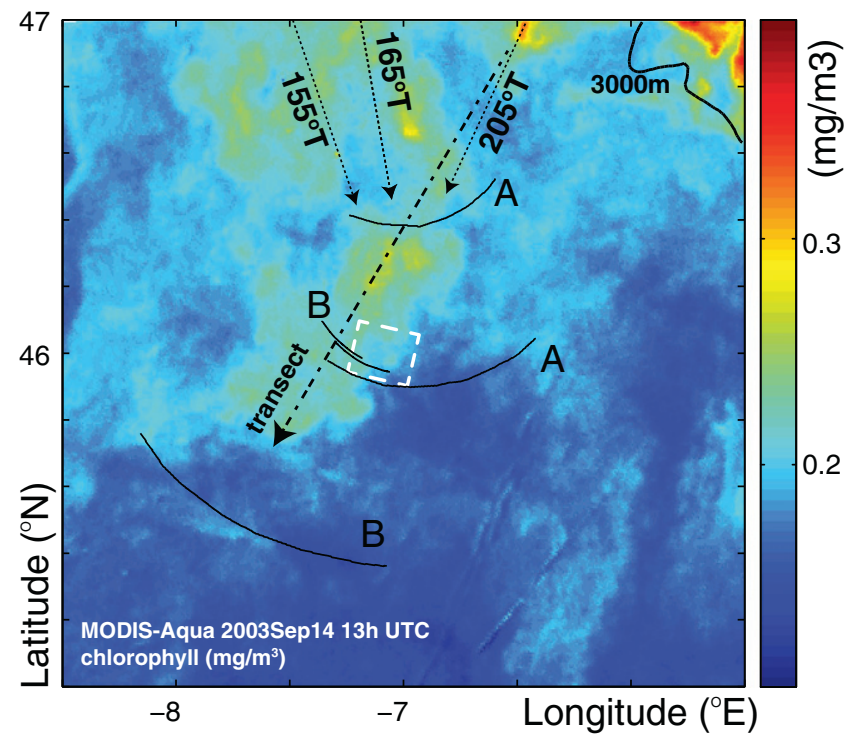

Fig. 4. Chlorophyll-a concentrations (in $\mathrm{mg} \cdot \mathrm{m}^{-3}$ ) based on a MODIS-Aqua image dated 14 September 2003 (acquired at $13 \mathrm{~h}$ UTC), overlaid with the positions of the leading waves of every ISW train observed in the corresponding level-1B product (see black lines), which were labelled A and B according to their approximate directions of propagation (also shown in dashed black arrows). The white dashed rectangle depicts the approximate location of Fig. 5a, while the dashed black line corresponds to the transect data shown in Fig. $6 \mathrm{~b}$. The $3000 \mathrm{~m}$ depth contour is also shown for reference.
The sunglint image reveals high ISW activity consistent with our previous analysis made from Fig. 2, including the two different propagation directions, one towards the southwest (B-type waves) and another towards the south-southeast (A-type waves). Furthermore, the long crest-lengths seen close to $46^{\circ} \mathrm{N},-7^{\circ} \mathrm{E}$, where the locally generated ISWs are already fully developed, can be used to infer the locations of their corresponding IT troughs and crests (the ISWs are phase-locked with the troughs of the IT). This is of key importance, when comparing the ITs locations with the ocean colour data and the pronounced regions of enhanced chlorophyll-a concentration levels. In particular, a large patch with an approximate circular configuration can be clearly seen close to $46.3^{\circ} \mathrm{N},-7.1^{\circ} \mathrm{E}$. This location is where ITs are likely to intersect and where their corresponding crests (located between two adjacent ISW packets along their propagation direction) are expected to interact constructively. In addition, this image also shows a smaller region of elevated chlorophyll-a concentrations, located farther north (near $46.7^{\circ} \mathrm{N},-7.0^{\circ} \mathrm{E}$ ), but coincident with the region where the IT beams generated at $G_{1}$ are expected to impact the thermocline (see also Fig. 3). The authors believe this smaller patch might be a consequence of the IT re-emergence process, previously generated from the critical slopes in region $G_{1}$, which is expected to induce significantly large amplitude oscillations in the seasonal thermocline (see e.g. Pichon et al., 2013).

Finally, Fig. 5a presents an RGB composite from an Envisat-MERIS acquisition made on the following day (i.e. September 15, 2003) at $10 \mathrm{~h} 52$ m UTC, and close to the region where A and B-type waves intersect (see white dashed rectangle in Fig. 4 for location). The ISW field shown in this example is very similar to the one depicted in Fig. 4 (and Fig. 2), and 2 packets of ISWs can also be seen propagating in the central region of the Bay of Biscay with a general southern direction. The sea surface signatures seen in this example aim to illustrate their appearance in typical sunglint images, from which several characteristics of the IW field can be estimated - including locations needed for this particular study, as the ones exhibited in Fig. 4. The high frequency character of the individual solitary waves can also be clearly distinguished in Fig. 5a, both in the image itself, and in representative transects taken perpendicular to the wave crests (Fig. 5b). Fig. 5b presents such an example matching the black rectangle, running along the ISW packet closer to the southern edge of the image, where the rank-ordered nature of these waves is again clearly displayed. We also note that the MERIS acquisition was used as a typical example of sunglint ISW imagery, rather than the level-1B image from Fig. 4, since the MODIS image is not as clear, probably owing to less favourable sunglint geometry between the satellite and the ISWs positions at the time of satellite overpass.

\section{Comparison with model results}

Optical remote sensing has an advantage over microwave sensors, which is the capability to observe in depth, for at least several tens of metres down in the ocean, depending on the water case (for more details see Smith, 1981).

Using the same methodology as da Silva et al. (2002), as well as a similar parameterization for the amplitude of the ITs and for the chlorophyll vertical profiles, we now seek to understand how the chlorophyll vertical displacements can effectively explain the remotely sensed ocean colour observations from September 14, 2003. Note that, the main reason for choosing this particular event is because the corresponding MODIS-Aqua image is completely cloud-free (other examples can be found in the NASA Ocean Colour archive).

According to Fig. 6a, a two layer model is used to assume that a DCM exists between $h_{1}$ and $h_{2}$ (with $\mathrm{h}_{2}$ deeper than $\mathrm{h}_{1}$ ), where the chlorophyll concentration is uniform and equal to $c_{\mathrm{b}}+c_{0}$, while elsewhere the concentration is equal to the background value $c_{\mathrm{b}}$. We then consider the propagation of a sinusoidal (tidal) wave of amplitude $a$ (with a $<h 1$ ), which travels in the $x$ direction, and modulates the DCM layer by simply moving it upwards and downwards, such that 


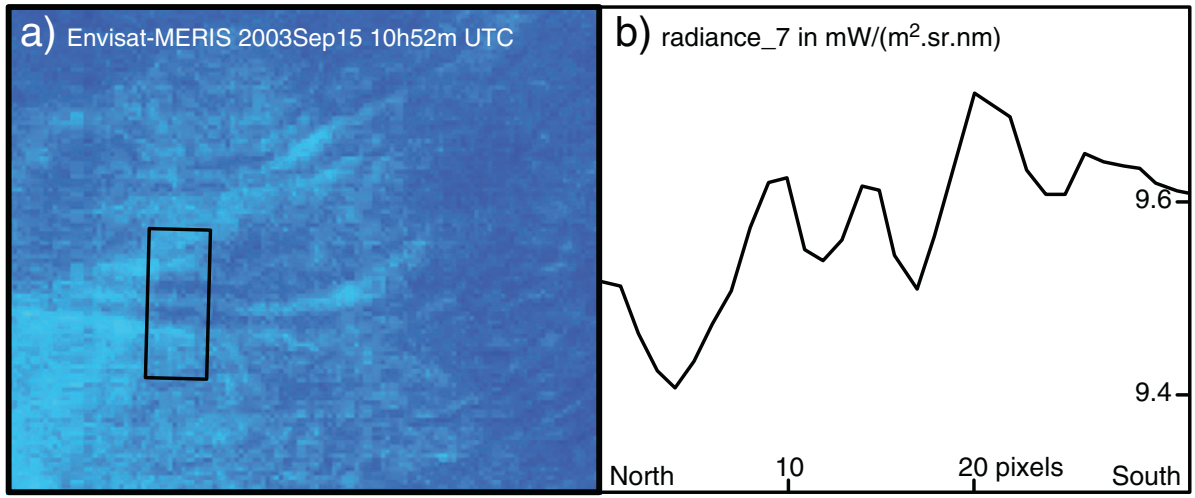

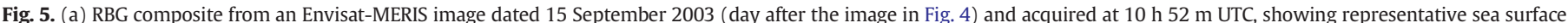

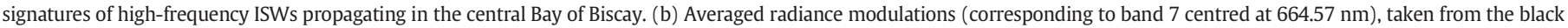
rectangle and showing rank-ordered amplitudes for the leading packet in Fig. $5 \mathrm{a}$. The distance scale is defined in pixels, relative to the northern end of the profile.

the depth distribution of the chlorophyll concentration may be written as:

$c(z)=\left\{\begin{array}{lr}c_{b} & \text { for } z<h_{1}+a \cos \left(\frac{2 \pi}{\lambda} x-\omega t\right) \\ c_{b}+c_{0} \text { for } h_{1}+a \cos \left(\frac{2 \pi}{\lambda} x-\omega t\right) \leq z \leq h_{2}+a \cos \left(\frac{2 \pi}{\lambda} x-\omega t\right) \\ c_{b} \quad \text { for } z>h_{2}+a \cos \left(\frac{2 \pi}{\lambda} x-\omega t\right)\end{array}\right.$

where $z$ is directed downwards (contrary to Eq. (2)), $2 \Pi / \lambda$ is the wavenumber of the tidal wave ( $\lambda$ being the wavelength), and $\omega$ its frequency.

To be able to compare the model's results with those obtained in the previous section, it is also important to note that the chlorophyll levels measured by the satellite $\left(c_{\text {sat }}\right)$ can be expressed as (Smith, 1981):

$c_{\text {sat }}(z)=\int_{0}^{z_{90}} c(z) g(z) d z / \int_{0}^{z_{90}} g(z) d z$

where the integrand term $g(z)=\exp (-2 K z)$, and $z_{90}$ is defined as the depth above which $90 \%$ of diffusely reflected irradiance originates. Note that, $z_{90}$ is also considered as the depth to which the sensor actually "sees", and can be given as the inverse of $K$, which is the diffuse attenuation coefficient for downwelling irradiance (see Kirk, 1996). Therefore, when $z_{90}<\mathrm{h}_{1}+\mathrm{a} \cos \left(\frac{2 \pi}{\lambda} \mathrm{x}-\omega \mathrm{t}\right)$ it is clear that $c_{s a t}=c_{\mathrm{b}}$. However, when $h_{1}+a \cos \left(\frac{2 \pi}{\lambda} x-\omega t\right) \leq z_{90} \leq h_{2}+a \cos \left(\frac{2 \pi}{\lambda} x-\omega t\right)$, then $c_{\text {sat }}=c_{b}+\frac{c_{0}\left[\exp \left\{-2 K\left(h_{1}+a \cos \left(\frac{2 \pi}{\lambda} x-\omega t\right)\right\}\right]-\exp \left\{-2 K z_{90}\right\}\right.}{\left[1-\exp \left\{-2 K z_{90}\right\}\right]}$.

We used typical values for the Bay of Biscay in this model, which means that: the mean thermocline depth was set to $50 \mathrm{~m}$, and the IT amplitude $a$ was defined to be as $20 \mathrm{~m}$, with a wavelength of $50 \mathrm{~km}$ (derived from SAR images, see Fig. 2). In addition, we also consider a DCM with a $30 \mathrm{~m}$ thickness, centred at the mean depth of the thermocline, and with chlorophyll levels enhanced by an amount of $0.3 \mathrm{mg} . \mathrm{m}^{-3}$ (i.e. $c_{0}$ ) over the background value. In turn, the chlorophyll background value $\left(0.2 \mathrm{mg} . \mathrm{m}^{-3}\right)$ was derived from the satellite image in the area surrounding the chlorophyll patches, but still well outside them, in order not to be influenced by the presence of IT activity. Finally, $K$ was defined as $0.05 \mathrm{~m}^{-1}$, which implies that $\mathrm{z}_{90}=20 \mathrm{~m}$.

The parameters chosen above allow the modelled chlorophyll (i.e. $c_{\text {sat }}$ ) distribution to be compared with the observed levels of chlorophyll along the transect defined by a dashed-dotted black line in Fig. 4 (i.e. concerning B-type waves). Note also, that the locations of the two ISW packets (centred at $45.5^{\circ} \mathrm{N},-7.8^{\circ} \mathrm{E}$ and at $46.0^{\circ} \mathrm{N}$, $-7.3^{\circ} \mathrm{E}$ ) were used to determine the positions of the IT troughs. In
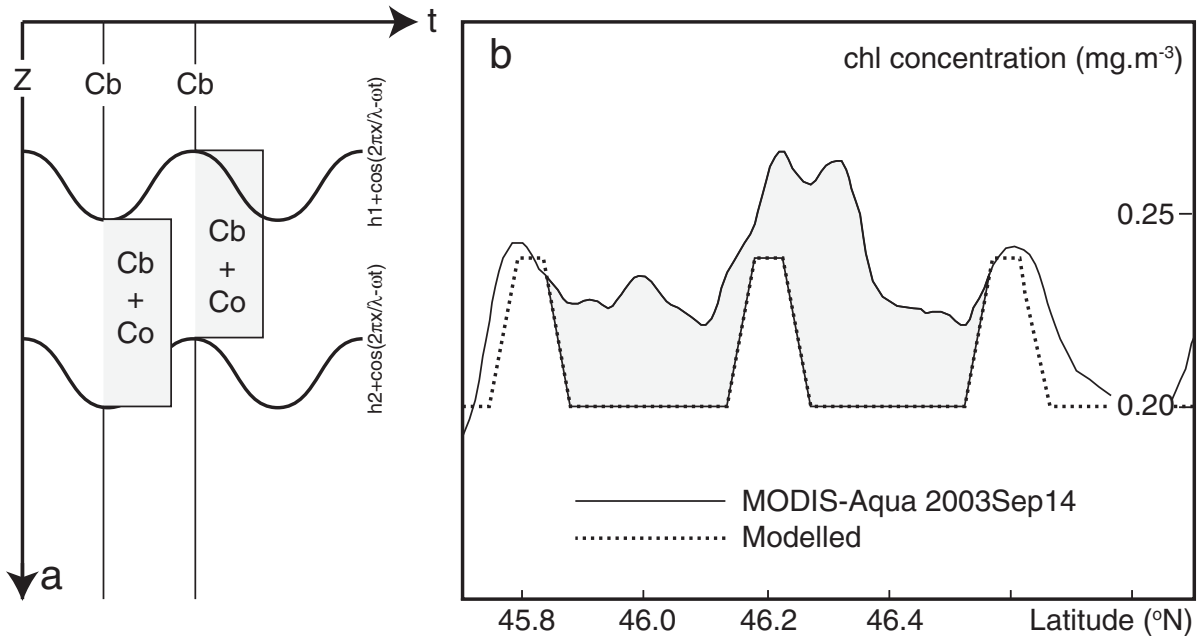

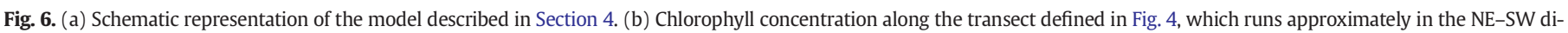
rection (about $210^{\circ} \mathrm{T}$ ), as observed by MODIS-Aqua on 14 September 2003 (solid black line), and its corresponding modelled results (dashed black line). See text for more details. 
turn, these positions were combined with the waves' propagation speeds to yield other "previous" locations of the IT trough (i.e. farther to northeast), which are an essential input for the model.

Satellite chlorophyll-a concentrations from September 14 (2003) and modelled $c_{s a t}$ values along the propagation direction of the B-type ISWs (and thus the associated IT) generated at $G_{2}$ are shown in Fig. 6b. The modelled chlorophyll concentration (se dashed line) is in good agreement with the locations of the first and last maxima $\left(45.8^{\circ} \mathrm{N}, 46.6^{\circ} \mathrm{N}\right)$, which in turn are coincident with the presence of IT crests - the minimum chlorophyll concentration around $46.8^{\circ} \mathrm{N}$ is also consistently shown in both cases. The most significant difference between the measured and modelled results consists of a large region between $46.0^{\circ} \mathrm{N}$ and $46.4{ }^{\circ} \mathrm{N}$, where the observed chlorophyll concentration (solid line) is significantly higher $\left(\sim 0.03 \mathrm{mg} \cdot \mathrm{m}^{-3}\right)$ than the model results.

Despite this quantitative difference, it is possible to see that the location of the modelled IT crest close to $46.2^{\circ} \mathrm{N}$ matches reasonably well with the location of the chlorophyll-a maximum measured near 46.3 ${ }^{\circ} \mathrm{N}$ in the satellite image. We stress that this is the region where the interaction of ITs (and the interference of the corresponding IT crests) is seen to occur (see Figs. 4 and 6). Therefore, the difference in chlorophyll concentration between the model and the satellite observations is here interpreted as directly related to the effect of a positive interference between IT crests propagating in different directions (i.e. wave types A and B). Note that, da Silva et al. (2002) showed similar results to those presented here in Fig. 6 (see also their Fig. 3 for comparison), but without the atypical enhanced patterns of chlorophyll that we observe near $46.3^{\circ} \mathrm{N}$.

\section{Discussion}

Satellite data presented in this paper (in particular SAR and sunglint imagery) provided evidence for two different IT propagation directions in the central Bay of Biscay, which converge in a region centred close to $46^{\circ} \mathrm{N},-7^{\circ} \mathrm{E}$. This region is also described by Pingree and New (1995) as an elliptical "eye", who anticipated strong interactions there between ITs coming from different generation sites along the French shelfbreak. Recent efforts have come to further support those conclusions, both via in situ data and modelling results (see Pichon et al., 2013).

We have shown that the ITs converging to this region are likely generated from different 'hotspots' running along the French shelf-break. A plausible generation mechanism has been identified for the A-type ISWs (cf. Fig. 3), which were found to be locally generated from ITs coming from the critical slopes found at the elevated body force region labelled $G_{1}$ in Fig. 3a. Note that, while the local generation hypothesis had already been discussed for B-type waves (see e.g. New and da Silva, 2002), the generation mechanism for A-type waves had not been previously discussed in the literature. Furthermore, the Baines (1982) barotropic tidal forcing in Fig. 3a is consistent with that already presented in Pichon et al. (2013, see their Fig. 4). However, they did not discuss its relevance for the local generation mechanism, nor did they investigate its consistency with remotely sensed data.

At the same time, the synergistic satellite approach, between ocean colour and near IR sensors, presented in Figs. 4 and 5 suggests that enhanced chlorophyll-a concentrations in the central Bay of Biscay are strongly correlated with a constructive interference between ITs propagating along two different axes. These waves are then expected to interact and originate enhanced vertical amplitudes, meaning that their crests will effectively be displaced towards the surface with larger vertical excursions.

It is interesting to note that, the chlorophyll-a patches presented in Fig. 4 are representative of many other examples taken from the same region (not shown). These results suggest that ITs interact close to $46{ }^{\circ} \mathrm{N},-7{ }^{\circ} \mathrm{E}$, where they usually form near-circular patches of enhanced chlorophyll-a in ocean colour images. This is a very different result from that presented by da Silva et al. (2002), where extended surface bands were observed instead in a direction perpendicular to the propagation axis of the ITs. We therefore suggest, that these near-circular elevated chlorophyll-a patches are a consequence of the interaction of long and well-developed ITs (with crest-lengths exceeding $50 \mathrm{~km}$, as revealed by their associated ISWs), which change the phytoplankton vertical distribution in regions as large as $30 \mathrm{~km}$ in diameter (see Fig. 4).

Furthermore, Fig. 6 presents smaller chlorophyll concentrations obtained from our model simulations (when comparing with observed satellite patch), precisely in the crossing range of different ITs (see also Fig. 4). It is very likely that the mismatch between the modelled chlorophyll concentration and the satellite observations (i.e. the grey area in Fig. 6) is related with significantly larger oscillations of the thermocline owing to IT interactions, which takes place where IT crests interfere constructively (centred at $46.3^{\circ} \mathrm{N},-7.0^{\circ} \mathrm{E}$ ). In such circumstances, those vertical movements would lead phytoplankton cells to undergo larger vertical displacement, which should appear as a measurable response in satellite chlorophyll products - significantly higher in concentration and total area than for a single IT. As a consequence, ocean colour remote sensors would then "see" an additional portion of the uplifted DCM covering a larger area in the satellite images.

It is important at this stage to consider other processes capable of influencing the ocean colour chlorophyll-a concentrations, which could be causing the individual effects discussed thus far for ITs. For instance, the enhanced phytoplankton activities in this study region could also result from Ekman pumping related processes such as eddies or Swoddies (see Pingree and Le Cann, 1992), or even from mixing with high-chlorophyll near-shelf waters. However, time series for the Upwelling Index (computed from http://las.pfeg.noaa.gov/las6_5/ servlets/dataset, see also Schwing et al., 1996 and Alvarez et al., 2010) taken for the central Bay of Biscay reveal practically no offshore transport for the time of our case study shown in Fig. 4 (as well as for others of the same kind, not shown). It is also unlikely that mixing with shelfbreak waters could cause these levels of enhanced chlorophyll concentrations so far from the shelf-break, and in such a localized fashion. In either case, all look-alike processes which could potentially be masking the IT effects discussed in the previous sections would be expected to average out in long term mean products.

Therefore, the question that now arises is whether or not this strong IW activity in the central Bay of Biscay, which is particularly intense in late summer, has any measurable effect on a larger timescale of ocean colour data. To investigate this hypothesis, we would require several images for similar events to that described earlier, which unfortunately are highly cloud contaminated. In fact, the major constraint in these investigations is clearly related to continuous cloud cover affecting this region, even during the summer period. To avoid this limitation, the monthly climatology from ocean colour data for late summer has been analysed, where the late summer period is defined here as the September months. September was chosen for two primary reasons, both resulting in the period where ISWs are stronger and more frequently observed. First, it agrees with the stronger stratification conditions (see e.g. Pingree and New, 1995), and second, has one of the two highest spring tides of the year (the other being in March).

The mean September chlorophyll-a concentration in the central region of the Bay of Biscay is presented in Fig. 7 (i.e. the $9 \mathrm{~km}$ level-3 product from MODIS-Aqua). In order to make a clear distinction between different influencing levels owing to the presence of ITs, we defined three regions south of the shelf-break, with $1^{\circ}$ square boxes, defined to be approximately parallel to the $200 \mathrm{~m}$ isobath and centred in agreement with the location of the elliptical 'eye'. Therefore, Fig. 7 aims to present a comparison among these different regions in the central Bay, which are affected by ITs to a different extent. Note also that, the centre box is centred close to $46.1^{\circ} \mathrm{N},-7.2^{\circ} \mathrm{E}$, and matches the area seen in the remotely sensed observations where strong IT wave activity and elevated chlorophyll-a patches were concentrated. 


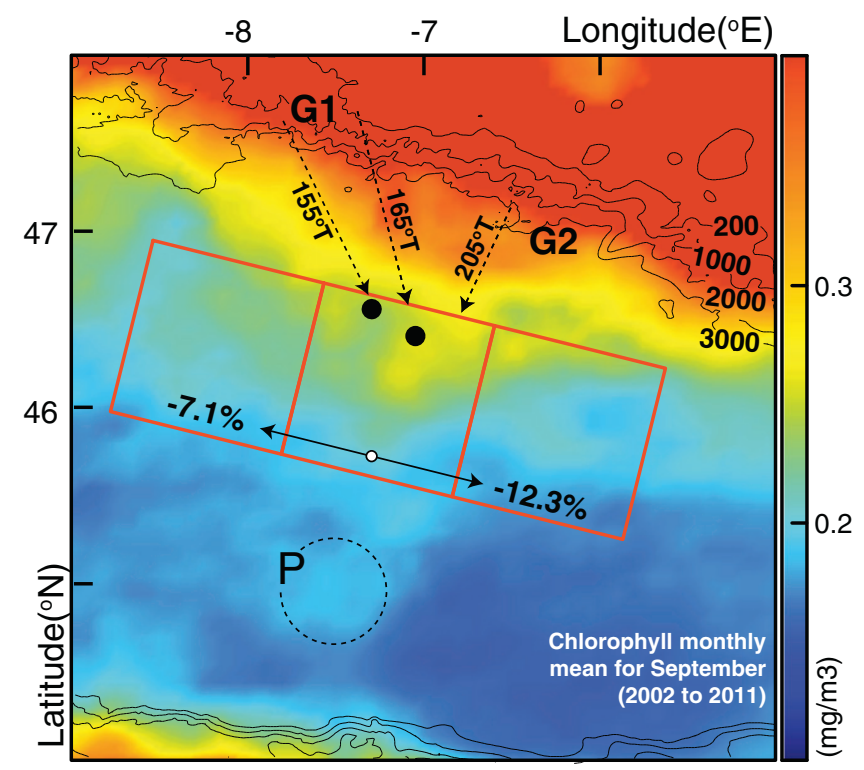

Fig. 7. Climatological (from 2002 to 2011) mean chlorophyll-a concentration (in mg.m ${ }^{-3}$ ) for September derived from MODIS-Aqua data in the central Bay of Biscay. The red rectangles represent areas where spatial averages have been calculated. The percentages indicated inside the two outer boxes are comparisons made with respect to the central box, which aims to be representative of enhanced IT activity. The locations of surfacing IT beams generated at G1 and G2 are also shown (see also Fig. 3). For reference, the dashed black circle labelled P marks a location of enhanced concentration discussed in Section 5.

The climatological September data (from 2002 to 2011) thus reveal that chlorophyll-a concentrations in the adjacent regions to the west and to the east of the central Bay of Biscay are 7.1 and 12.3\% lower, respectively (see Fig. 7). These differences in the average chlorophyll concentration suggest a significant effect owing to IT activity in this region, which is particularly pronounced in the central box due to the interaction of IT waves generated from $G_{1}$ and $G_{2}$ (see Fig. 3).

The anomaly in chlorophyll-a concentrations is about $10 \%$ more in the central box when compared with the adjacent regions, even when using monthly data to avoid the shorter-term responses, such as those associated with the uplifting of the DCM under the influence of the IT. This is in agreement with other related studies such as Pan et al. (2012), who showed that the mean monthly values of chlorophyll-a in a region of the South China Sea, due to IT activity were on average $19 \%$ higher than in the nearby areas that were minimally affected by their presence. Note that, despite our 10\% anomaly, the Bay of Biscay does not have "minimally" affected areas by ITs, since these are present in the adjacent regions as well (see Fig. 7 in New and da Silva, 2002; and Fig. 3 in Pichon et al., 2013).

Interestingly, Fig. 7 also reveals an additional pattern of elevated concentrations of chlorophyll-a close to $45.0^{\circ} \mathrm{N},-7.5^{\circ} \mathrm{E}$, although less expressive when compared with that discussed earlier. The authors stress that this region matches reasonably well with the model results shown in Pichon et al. (2013), which also exhibit a local maximum of the $\mathrm{M}_{2}$ IT amplitudes at this location (see Fig. 14a in Pichon et al., 2013). This particular signature detected on the September monthly mean presents a smaller anomaly, when compared with the one previously discussed, possibly because it is farther south and way of the region where the main IT interactions occur. However, this result reinforces the idea that large vertical disturbances over the thermocline are capable of influencing the near-surface chlorophyll distribution, even at large time scales.

These elevated chlorophyll-a concentration levels observed in monthly mean data might be of considerable importance, since IT activity may be leading to an increase in biomass due to their persistent activity over several days after spring tides. Under these circumstances, strong IT activity would increase the amount of available light to phytoplankton in a continuous fashion in the course of several days, due to repeated oscillations, and thus increase the primary production rates. We further note that, this hypothesis is also supported by previous model results (see Kamykowski, 1979; Muacho et al., 2013) that effectively showed an increase in productivity due to large-amplitude IT motion, associated however with shorter time-scales (up to 5 days). Considering that large IT waves occur periodically, and that interaction processes are known to occur in late summer around $46{ }^{\circ} \mathrm{N},-7^{\circ} \mathrm{E}$, the positive anomaly of about $10 \%$ in the mean September chlorophyll-a could therefore be interpreted as a biomass increase resulting from strong IT activity and consequent interaction, which is ultimately driven by the specific morphology of the northern (French) shelf-break of the Bay of Biscay.

\section{Conclusions}

In summary, this paper presents evidence for ITs propagating in two distinct directions from the northern French shelf-break, which interact in the central Bay of Biscay during late summer and after spring tides. The enhanced chlorophyll-a concentration levels, observed on MODISAqua imagery, are in close agreement with the locations where these ITs are expected to interact. The large chlorophyll-a patches observed in individual images at this location are most likely the result of positive interference between different IT crests. Moreover, this strong IT activity also presents ocean colour signatures on climatological satellite data during late summer (i.e. September) and we therefore suggest that there is a strong IW effect on the phytoplankton vertical dynamics. The chlorophyll-a concentration anomalies identified in the mean monthly data are significant, and indicate that IT activity has a relevant ecological impact over the central Bay of Biscay, especially in the late summer.

\section{Acknowledgements}

This work was undertaken as part of a PhD thesis (SFRH/BD/22561/ 2005), funded by the Portuguese FCT (Fundação para a Ciência e Tecnologia). One of the authors is also grateful for an FCT research grant (SFRH/BPD/84420/2012). We would like to thank NASA for the MODIS-Aqua data and ESA Project AOPT-2423 for providing the SAR images. This research was partially supported by projects PEst-C/ MAR/LA0015/2011 and PEst-OE/MAR/UI0199/2011, funded by FCT and the European Regional Development Fund (ERDF) through the COMPETE - Operational Competitiveness Programme as part of the National Strategic Reference Framework. We thank the three anonymous reviewers for their helpful comments, which we feel have helped to improve the paper significantly. The helpful support provided by Dr. Lynn Dewitt is also greatly acknowledged.

\section{References}

Akylas, T.R., Grimshaw, R.H.J., Clark, S.R., Tabaei, A., 2007. Reflecting tidal wave beams and local generation of solitary waves in the ocean thermocline. J. Fluid Mech. 593, 297-313. http://dx.doi.org/10.1017/S0022112007008786.

Alpers, W., 1985. Theory of radar imaging of internal waves. Nature (London) 314 , 245-247. http://dx.doi.org/10.1038/413245a0.

Alvarez, I., Gomez-Gesteira, M., de Castro, M., Gomez-Gesteira, J.L., Dias, J.M. 2010. Summer upwelling frequency along the western Cantabrian coast from 1967 to 2007. J. Mar. Syst. 79, 218-226. http://dx.doi.org/10.1016/j.jmarsys.2009.09.004.

Azevedo, A., da Silva, J.C.B., New, A.L., 2006. On the generation and propagation of internal waves in the southern Bay of Biscay. Deep-Sea Res. I 53, 927941. http://dx.doi.org/10. 1016/j.dsr.2006.01.013.

Baines, P.G., 1982. On internal tides generation models. Deep Sea Res. Part A 29, 307-338. http://dx.doi.org/10.1016/0198-0149(82)90098-X.

da Silva, J.C.B., Ermakov, S.A., Robinson, I.S., Jeans, D.R.G., Kijashko, S.V., 1998. Role of surface films in ERS SAR signatures of internal waves on the shelf. 1. Short-period internal waves. J. Geophys. Res. 103 (C4), 8009-8031. http://dx.doi.org/10.1029/ 97JC02725. 
da Silva, J.C.B., New, A.L., Srokosz, M., Smyth, T., 2002. On the observability of internal tidal waves in remotely-sensed ocean color data. Geophys. Res. Lett. 29 (12), 1569-1572. http://dx.doi.org/10.1029/2001GL013888.

da Silva, J.C.B., New, A.L., Azevedo, A., 2007. On the role of SAR for observing "Local Generation" of internal solitary waves off the Iberian Peninsula. Can. J. Remote. Sens. 33, 388-403. http://dx.doi.org/10.5589/m07-041.

da Silva, J.C.B., New, A.L., Magalhaes, J.M., 2009. Internal solitary waves in the Mozambique Channel: observations and interpretation. J. Geophys. Res. 114, C05001. http://dx.doi. org/10.1029/2008JC005125.

Egbert, G.D., Erofeeva, S.Y., 2002. Efficient inverse modeling of barotropic ocean tides. J. Ocean. Atmos. Technol. 19, 183-204. http://dx.doi.org/10.1175/1520-0426(2002) 019<0183:EIMOBO >2.0.CO;2.

Ermakov, S.A., da Silva, J.C.B., Robinson, I.S., 1998. Role of surface films in ERS SAR signatures of internal waves on the shelf: 2. Internal tidal waves. J. Geophys. Res. 103 (C4), 8033-8043. http://dx.doi.org/10.1029/97JC02724.

Gaxiola-Castro, G., Alvarez-Borrego, S., Najera-Martinez, S., Zirino, A.R., 2002. Internal waves effect on the Gulf of California phytoplankton. Cienc. Mar. 28, 297-309.

Gerkema, T., 2001. Internal and interfacial tides: beam scattering and local generation of solitary waves. J. Mar. Res. 59, 227-255. http://dx.doi.org/10.1357/002224001762882646.

Grisouard, N., Staquet, C., Gerkema, T., 2011. Generation of internal solitary waves in a pycnocline by an internal wave beam: a numerical study. J. Fluid Mech. 676, 491-513. http://dx.doi.org/10.1017/jfm.2011.61.

Harlay, J., Borges, A.V., Van Der Zee, C., Delille, B., Godoi, R.H.M., Schiettecatte, L.-S. Roevros, N., Aerts, K., Lapernat, P.-E., Rebreanu, L., Groom, S., Daro, M.-H., Van Grieken, R., Chou, L., 2010. Biogeochemical study of a coccolithophorid bloom in the northern Bay of Biscay (NE Atlantic Ocean) in June 2004. Prog. Oceanogr. 86 317-336. http://dx.doi.org/10.1016/j.pocean.2010.04.029.

Harlay, J., Chou, L., De Bodt, C., Van Oostende, N., Piontek, J., Suykens, K., Engel, A., Sabbe, K. Groom, S., Delille, B., Borges, A.V., 2011. Biogeochemistry and carbon mass balance of a coccolithophore bloom in the northern Bay of Biscay (June 2006). Deep-Sea Res. I 58, 111-127. http://dx.doi.org/10.1016/j.dsr.2010.11.005.

Jackson, C.R., 2007. Internal wave detection using the moderate resolution imaging spectroradiometer (MODIS). J. Geophys. Res. 112, C11012. http://dx.doi.org/10. 1029/2007JC004220.

Jackson, C.R., Alpers, W., 2010. The role of the critical angle in brightness reversals on sunglint images of the sea surface. J. Geophys. Res. 115, C09019. http://dx.doi.org/ 10.1029/2009JC006037.

Kamykowski, D., 1979. The growth response of a model Gymnodinium splendens in stationary and wavy water columns. Mar. Biol. 50, 289-303.

Kirk, J.T.O., 1996. Light and Photosynthesis in Aquatic Ecosystems, Second edition. Cambridge Univ. Press, p. 528.

Mercier, M.J., Mathur, M., Gostiaux, L., Gerkema, T., Magalhaes, J.M., da Silva, J.C.B., Dauxois, T., 2012. Soliton generation by internal tidal beams impinging on a pycnocline: laboratory experiments. J. Fluid Mech. 704, 37-60. http://dx.doi.org/10. 1017/jfm.2012.191.

Muacho, S., da Silva, J.C.B., Brotas, V., Oliveira, P.B., 2013. Effect of internal waves on nearsurface chlorophyll concentration and primary production in the Nazare Canyon (west of the Iberian Peninsula). Deep-Sea Res. I 81, 89-96.
New, A.L., da Silva, J.C.B., 2002. Remote-sensing evidence for the local generation of internal soliton packets in the central Bay of Biscay. Deep-Sea Res. I 49, 915-934. http://dx.doi.org/10.1016/S0967-0637(01)00082-6.

New, A.L., Pingree, R.D., 1992. Local generation of internal soliton packets in the centra Bay of Biscay. Deep Sea Res. Part A 39, 1521-1534. http://dx.doi.org/10.1016/0198 0149(92)90045-U.

Pan, X.-J., Wong, G.T.F., Shiah, F.-K., Ho, T.-Y., 2012. Enhancement of biological productivity by internal waves: observations in the summertime in the northern South China Sea. J. Oceanogr. http://dx.doi.org/10.1007/s10872-012-0107-y.

Pichon, A., Correard, S., 2006. Internal tides modelling in the Bay of Biscay. Comparisons with observations. Sci. Mar. 70 (S1), 65-88. http://dx.doi.org/10.3989/scimar.2006. 70 s165.

Pichon, A., Morel, Y., Baraille, R., Quaresma, L.S., 2013. Internal tide interactions in the Bay of Biscay: observations and modeling. J. Mar. Syst. 109-110, S26-S44. http://dx.doi. org/10.1016/j.jmarsys.2011.07.003.

Pingree, R.D., Le Cann, B., 1992. Anticyclonic eddy X91 in the southern Bay of Biscay May 1991 to February 1992. J. Geophys. Res. 97 (C9), 14353-14367. http://dx.doi org/10.1029/92JC01181.

Pingree, R.D., New, A.L., 1989. Downward propagation of internal tidal energy into the Bay of Biscay. Deep Sea Res. Part A 36, 735-758. http://dx.doi.org/10.1016/01980149(89)90148-9.

Pingree, R.D., New, A.L., 1991. Abyssal penetration and bottom reflection of internal tida energy in the Bay of Biscay. J. Phys. Oceanogr. 21, 28-39. http://dx.doi.org/10.1175/ 1520-0485(1991) 021<0028:APABRO>2.0.CO;2.

Pingree, R.D., New, A.L., 1995. Structure, seasonal development and sunglint spatial coherence of the internal tide on the Celtic and Armorican shelves and in the Bay of Biscay. Deep Sea Res. Part I 42, 245-284.

Pingree, R.D., Mardell, G.T., New, A.L., 1986. Propagation of internal tides from the upper slopes of the Bay of Biscay. Nature 312, 154-158. http://dx.doi.org/10.1038/321154a.

Sangra, P., Basterretxea, G., Pelegri, J.L., Aristegui, J., 2001. Chlorophyll increase due to internal waves on the shelf break of Gran Canaria (Canary Islands). Sci. Mar. 65 (1), 89-97.

Schwing, F.B., O'Farrell, M., Steger, J., Baltz, K., 1996. Coastal upwelling indices, west coast of North America, 1946-1995. U.S. Dept. of Commerce, NOAA Tech. Memo. NOAATM-NMFS-SWFC-231 (207 pp.).

Smith, R.C., 1981. Remote sensing and depth distribution of ocean chlorophyll. Mar. Ecol. Prog. Ser. 5, 359-361.

Smith, W.H.F., Sandwell, D.T., 1997. Global sea floor topography from satellite altimetry and ship depth soundings. Science 277 (5334), 1956-1962. http://dx.doi.org/10. 1126/science.277.5334.1956.

Thompson, D.R., Gasparovic, R.F., 1986. Intensity modulation in SAR images of internal waves. Nature 320, 345-348.

Vázquez, A Flecha, S., Bruno, M., Macías, D. Navarro, G. 2009. Internal waves and shortscale distribution patterns of chlorophyll in the Strait of Gibraltar and Alborán Sea. Geophys. Res. Lett. 36, L23601. http://dx.doi.org/10.1029/2009GL040959.

Wang, Y.H., Dai, C.F., Chen, Y.Y., 2007. Physical and ecological processes of internal waves on an isolated reef ecosystem in the South China Sea. Geophys. Res. Lett. 34, L18609. http://dx.doi.org/10.1029/2007GL030658. 